\title{
Prenatal sonographic diagnosis of limb-body wall complex
}

\begin{abstract}
Limb-body wall complex (LBWC) is a rare condition characterized by multiple, severe congenital abnormalities in a fetus. It typically results in openings in the anterior body wall (chest and belly) and defects of the limbs (arms and legs). In LBWC the fetus is usually found in an abnormal position in the uterus with the belly or the back stuck against the placenta. Other aspects of LBWC may include anencephaly, encephalocele, facial clefts, scoliosis, abnormalities of the urogenital organs and short umbilical cord. Karyotyping is usually normal but the prognosis is lethal.
\end{abstract}

Keywords: omphalocele, gastroschisis, amniotic bands, limb-body wall complex
Volume 6 Issue 3 - 2017

\section{Lemaire, HA Dolleman, I Davilmar, JE Aupont}

Rita Merli Maternity Hospital, Saint Damien Hospital, Our Little Brothers and Sisters, UK

\begin{abstract}
Correspondence: JE Aupont, Harris Birthright Research Centre for Fetal Medicine, King's College Hospital, London, UK, Email jeanedgardaupont@gmail.com
\end{abstract}

Received: November 13, 2017| Published: December 18, 2017

\section{Case history}

A 23-year-old multigravida (G3P2) came to our unit for PPROM (Premature Preterm Rupture of Membranes) at $31{ }^{6 / 7}$ weeks gestation. She reported lower abdominal pain and was leaking amniotic fluid. This was confirmed by checking the cervix using a speculum. An ultrasound exam was performed which showed a fetus in breech position with the spine on the maternal left hand side. The head appeared normal and its size was consistant with the gestational age. The abdominal circumference could not be measured and it was difficult to differentiate the upper from the lower limbs. The liver, the stomach and the intestines were herniated through a severe abdominal wall defect. The fetus was moving slightly and had normal BPM. ${ }^{1-6}$ We were unable to see the gender of the fetus. Another scan performed the following day depicted a scoliosis, amniotic bands and a short umbilical cord. The gender remained unidentified. At that point the diagnosis of LBWC was made. The fetus was stillborn at 1445 grams after a spontaneous labor that took place the day after. The diagnosis was confirmed after birth. The gender was not visible.

\section{Discussion}

Two main phenotypes have been described in the literature:

i. Fetuses with craniofacial defects

ii. Fetuses without craniofacial defects

Different pathogenic mechanisms have been proposed for these phenotypes: an early rupture of the amnion; vascular disruption; and an intrinsic abnormal embryonic development especially the embryonic folding. More recently it has been suggested a potential genetic origin of the complex involving mutation in genes responsible for laterality. Our diagnosis was based on the presence of scoliosis and short cord along with a major abdominal defect (Figures 1-6).

i. Differential diagnosis: Omphalocele, Gastroschisis.

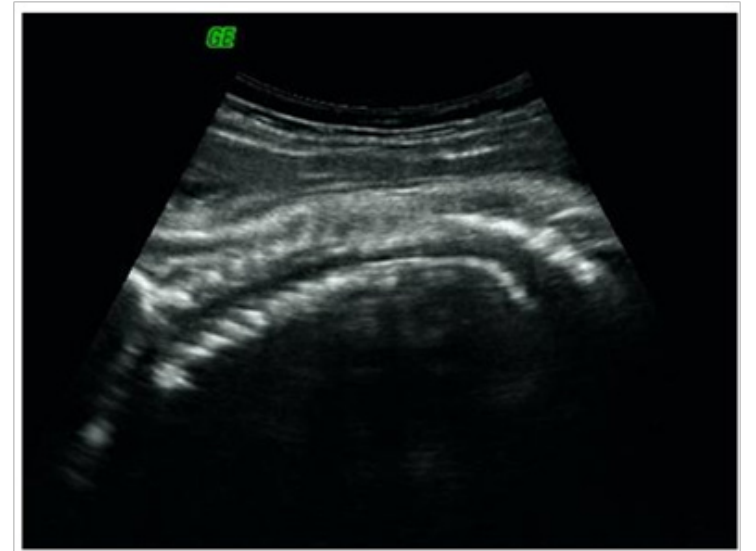

Figure I Scoliosis.

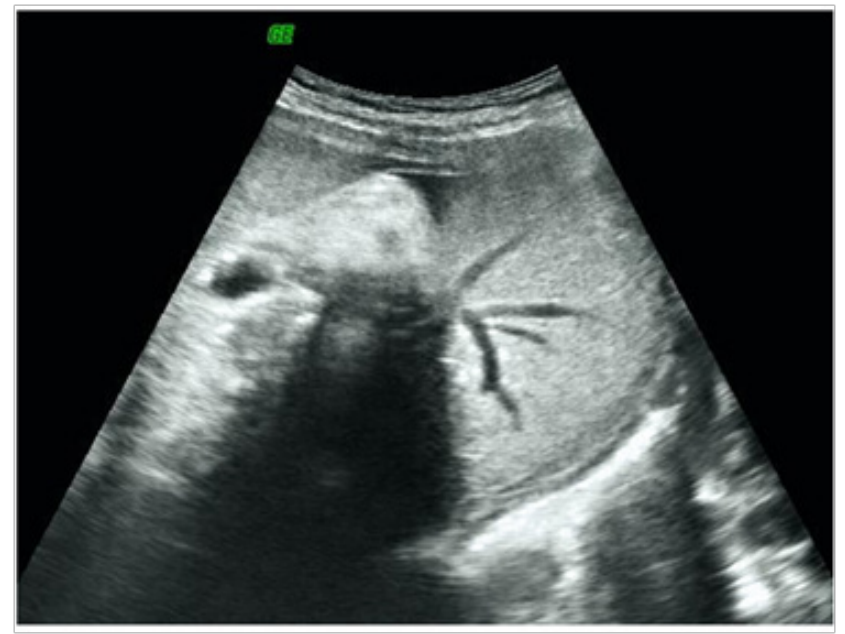

Figure 2 Liver. 


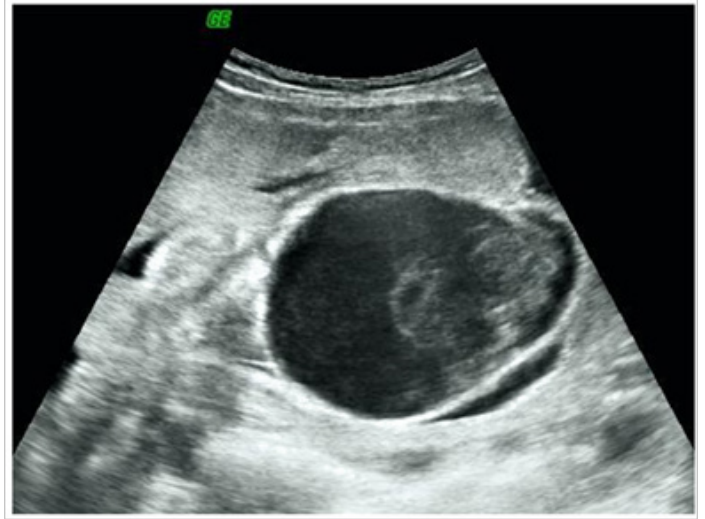

Figure 3 Stomach.

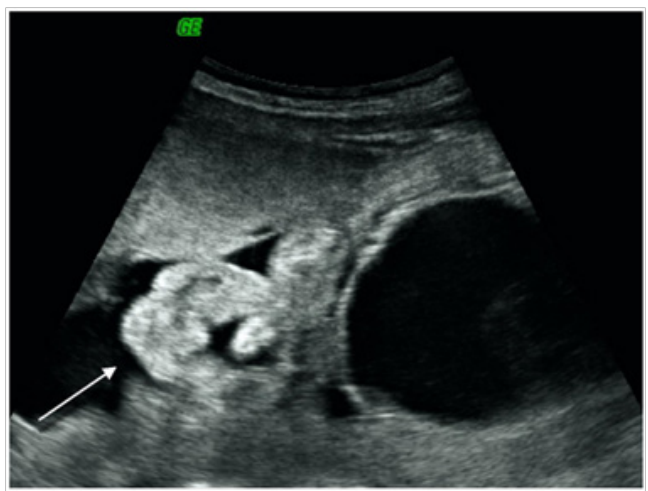

Figure 4 Intestines.

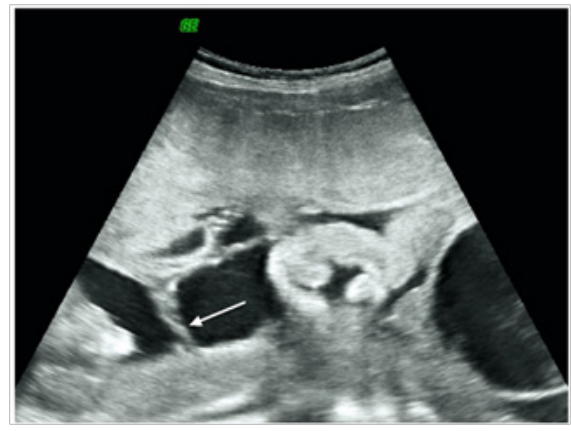

Figure 5 Amniotic band.

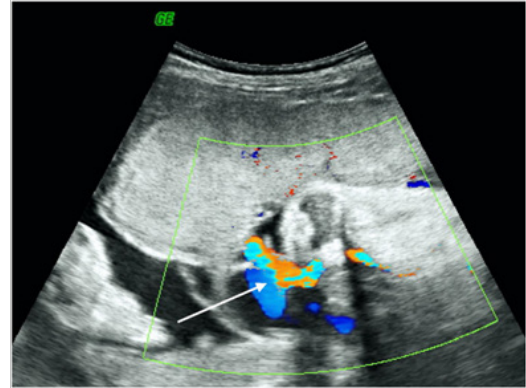

Figure 6 Short umbilical cord.

\section{Conclusion}

The prognosis of LBWC is very poor and termination of pregnancy is offered once the diagnosis is confirmed. Careful ultrasound of the foetus should therefore be undertaken whenever ventral wall defect is suspected. To the best of our knowledge, this is the first case report from a Haitian centre where the diagnosis was made in the antenatal period and confirmed after birth.

\section{Acknowledgements}

None.

\section{Conflict of interest}

The author declares no conflict of interest.

\section{References}

1. Prasun P, Behera B, Pradhan M. Limb body wall complex. Indian Journal of Pathology and Microbiology. 2008;51(2):255-256.

2. Rachad M, Chaara H, Bouguern H, et al. Limb body wall complex: à propos d'une observation assez particulière. The PanAfrican Medical Journal. 2012;11:20

3. Gajzer DC, Hirzel AC, Saigal G, et al. Possible genetic origin of limb-body wall complex. Fetal Pediatr Pathol. 2015;34(4):257-270.

4. Chen CP, Lin CJ, Chang TY, et al. Second-trimester diagnosis of limbbody wall complex with literature review of pathogenesis. Genet Couns. 2007;18(1):105-112.

5. Pumberger W, Schaller A, Bernaschek G. Limb-body wall: a compound anomaly pattern in body-wall defects. Pediatr Surg Int. 2001;17(5-6):486490.

6. Echoscopie in de Monique C Haak, verloskunde en gynaecologie. In: John MG editor. 4th ed. USA: Dick Oepkes, Mark Hans Emanuel; 2013. 